\title{
Clinical indicators of surgical outcomes after cervical single open-door laminoplasty assessed by the Japanese Orthopaedic Association Cervical Myelopathy Evaluation Questionnaire
}

\author{
Narihito Nagoshi ${ }^{1} \cdot$ Osahiko Tsuji ${ }^{1} \cdot$ Eijiro Okada ${ }^{1} \cdot$ Nobuyuki Fujita $^{1} \cdot$ Mitsuru Yagi ${ }^{1} \cdot$ Takashi Tsuji $^{2} \cdot$ \\ Masaya Nakamura $^{1} \cdot$ Morio Matsumoto $^{1} \cdot$ Kota Watanabe $^{1}$
}

Received: 23 November 2018 / Revised: 19 January 2019 / Accepted: 24 January 2019 / Published online: 21 February 2019

(c) International Spinal Cord Society 2019

\begin{abstract}
Study design Retrospective cohort study.

Objectives The old-version JOA score for cervical myelopathy $(\mathrm{CM})$ is an evaluation system performed by medical providers that focuses only on neurological function. The purpose of this study was to evaluate patient-reported outcomes using the Japanese Orthopaedic Association Cervical Myelopathy Evaluation Questionnaire (JOACMEQ), and to clarify clinical factors that affect the therapeutic effectiveness for CM.

Setting Single institute in Japan.

Methods We reviewed surgical outcomes for $126 \mathrm{CM}$ patients who were treated by single open-door laminoplasty and were followed at least 2 years. We assessed clinical information, JOACMEQ, JOA scores, and radiographic parameters. Patients were grouped according to effective or ineffective surgical outcomes as defined by the JOACMEQ using logistic regression analyses.

Results Laminoplasty resulted in functional improvement in the cervical spine and extremities for $40-50 \%$ of the patients, while bladder function showed only minimal recovery. Multivariable analyses revealed that a significant postoperative reduction in neck or shoulder pain influenced the effective functional recovery of the cervical spine. A reduction in arm or hand pain favorably affected the postoperative upper extremity function. Lower age and a postoperative decrease in limb pain were correlated with significantly improved function of the lower extremities. A postoperative reduction in arm pain enhanced the QOL recovery.

Conclusions The JOACMEQ makes it possible to analyze multiple aspects of surgical outcomes for patients who undergo cervical spine surgery. Open-door laminoplasty did not provide favorable results for some patients, which highlights the importance of assessing the indications for this procedure and managing postoperative pain.
\end{abstract}

Supplementary information The online version of this article (https:// doi.org/10.1038/s41393-019-0258-4) contains supplementary material, which is available to authorized users.

Kota Watanabe

watakota@gmail.com

1 Department of Orthopaedic Surgery, Keio University School of Medicine, Tokyo, Japan

2 Department of Orthopaedic Surgery, Fujita Health University, Toyoake, Japan

\section{Introduction}

Cervical spondylotic myelopathy (CSM) and ossification of the posterior longitudinal ligament (OPLL) cause neurological deficits by compressing the spinal cord. This compression can often be relieved surgically. Numerous studies have demonstrated the benefits of unilateral open-door laminoplasty for cervical myelopathy [1-3].

The old version of the Japanese Orthopaedic Association scoring system (JOA score) is often used to assess surgical outcomes in Asia, and the modified JOA score is widely used in other regions [4-6]. The JOA scoring system, although widely accepted [5, 7], is based on evaluation from the medical providers' perspective, and only includes neurological function [8]. Notably, the JOA score does not 
include the patient's satisfaction, disability, handicaps, or general health, which can all be affected by cervical myelopathy [8]. The Neck Disability Index, which is frequently used to assess clinical outcomes [9], focuses on the impact of neck pain on daily activity and cannot comprehensively evaluate the effect of cervical spinal surgery.

The JOA Cervical Myelopathy Evaluation Questionnaire (JOACMEQ) was developed to measure clinical outcomes in patients with cervical myelopathy [8, 10-13] (Supplementary figure). The JOACMEQ primarily evaluates patient-reported outcomes such as quality of life (QOL) and function of the cervical spine, upper extremities, lower extremities, and bladder. The JOACMEQ is modified from a portion of the Short-Form 36-Item Health Survey (SF-36), which measures health status and QOL [8], and is closely correlated with the SF-36 [14]. While the SF-36 is used broadly for spinal diseases and other pathological conditions, the JOACMEQ more specifically evaluates outcomes for cervical myelopathy. The JOACMEQ has been translated into several languages and has gained widespread international use [15-17]. The JOACMEQ assesses therapeutic effectiveness by evaluating changes between preoperative and postoperative scores [10], and logistic regression analysis can then be used to investigate indicators that affect surgical outcomes by grouping patients according to whether their outcomes are effective or ineffective [18]. This information helps to identify critical issues in surgical treatment and ways to improve strategies for treating cervical myelopathy.

Previous studies that used the JOACMEQ to assess treatments for cervical myelopathy had concerns about small sample sizes and short follow-up periods [15, 19-21]. Moreover, there are no comprehensive studies evaluating the clinical outcomes after expansive single open-door laminoplasty using the JOACMEQ. Therefore, here we sought to identify important indicators of effective outcomes for single open-door laminoplasty and to determine the impact of this procedure on functional recovery, disability, and QOL outcomes using the JOACMEQ.

\section{Methods}

\section{Participants}

This study included 126 patients with clinically and radiographically confirmed CSM or OPLL who were treated by expansive single open-door laminoplasty [2] at one institution between 2008 and 2014.

Patients were included if they (1) presented with at least one clinical sign of myelopathy, (2) showed cervical spinal cord compression on magnetic resonance imaging or computed tomography, and (3) had no previous cervical spine surgery. Patients were eligible even if the decompressed range extended to thoracic levels. Patients were excluded if they were asymptomatic, were diagnosed with active infection, neoplastic spinal disease, rheumatoid arthritis, or ankylosing spondylitis, or had been treated for osteoarthritis of the hip or knee with concomitant lumbar canal stenosis.

\section{Surgical procedure}

Nine of our board-certified spinal surgeons performed all of the surgeries. Expansive single open-door laminoplasty was performed as described previously [1-3]. Briefly, the laminae were exposed through a midline incision followed by dissection of the bilateral paracervical muscles. A drill was used to make a gutter at the junction of the lamina and facet joint, and the ventral cortex of the lamina was perforated. Another gutter was made in the opposite side as a hinge, and the laminar door was lifted and fixed in the expanded position with sutures or plates (Centerpiece ${ }^{\mathrm{TM}}$ Plate Fixation System; Medtronic Sofamor Danek, USA). Patients began walking without a brace the day after surgery.

\section{Data collection}

We retrospectively collected demographic information, medical history, and imaging data, and evaluated the functional status before surgery and at the final follow-up (at least 2 years after surgery) using old-version JOA scores and the JOACMEQ. We did not set a limit for the maximum follow-up duration. Pain, stiffness, and numbness were calculated by the Visual Analog Scale (VAS) included in the JOACMEQ. Surgery-related events within 30 days of surgery were defined as perioperative complications. All the data was uploaded as a Supplementary dataset.

The JOACMEQ defines effective treatment as (1) a posttreatment score $\geq 20$ points above the pretreatment score, or (2) a pretreatment score $<90$ and a posttreatment score $\geq 90$ [10]. Patients with both pretreatment and posttreatment scores $\geq 90$ were counted, but excluded from further analysis. A group's effective rate was calculated as [(number of patients judged "effective")/[(total number of patients in the group) - (number of patients with pre- and posttreatment scores $\geq 90)$ ].

\section{Imaging}

Cervical alignment was assessed by measuring the intermittent $\mathrm{C} 2-\mathrm{C} 7$ angles, determined by tangential lines on the posterior edge of the target vertebral bodies, on plain radiographs in the neutral position. We calculated the cervical range of motion (ROM) by subtracting the flexion from the extension $\mathrm{C} 2-\mathrm{C} 7$ angles. 


\section{Statistical analysis}

Continuous variables and frequencies are presented as means \pm standard deviation, and categorical variables as percentages. Changes between the preoperative and final JOA scores, VAS, C2-C7 angles, and ROM were assessed by paired $t$-tests. To compare the data between CSM and OPLL, the $t$-test was performed for JOA scores and radiographic findings. The significance of effective surgical parameters that were clinically related to each function or QOL was evaluated by univariate logistic analysis or chi square test. Factors with a $P$-value $<0.05$ in the univariate analysis were entered into the multivariable logistic model after multiplicity adjustment by the Bonferroni correction. All statistical analyses were performed using SPSS version 23.0 (SPSS Inc., Chicago, IL). $P$-values $<.05$ were considered significant.

\section{Results}

\section{Demographics and surgical characteristics}

Table 1 summarizes the demographics for 126 patients, including 102 men (81\%) and 24 women (19\%) aged 63.8 \pm 11.1 years on average. The average body mass index was $24.7 \pm 3.5$. The average duration of symptoms was $35.1 \pm$ 50.0 months. The number of patients with comorbidities was 73 (58\%): 42 (33\%) had hypertension, 19 (15\%) had diabetes mellitus, $11(9 \%)$ had cardiac disease, $3(2 \%)$ had renal disease, 10 (8\%) had malignant tumors, 5 (4\%) had cerebrovascular disease, and 2 (2\%) each had respiratory and psychiatric disease. None of the patients had a connective tissue disease. The pathology of the cervical myelopathy was CSM for 81 patients (64\%) and OPLL for 45 (36\%). The median follow-up duration was 3.0 years (range 2.0-5.0).

The surgical characteristics and perioperative complications are summarized in Table 2. The mean operative duration was $88.9 \pm 33.7 \mathrm{~min}$. The average number of operated laminae was $4.8 \pm 1.0$. The average hospital stay was $15.6 \pm 5.3$ days. Perioperative complications included segmental motor paralysis in five patients (4\%), surgical site infection in one $(1 \%)$, hematoma in three $(2 \%)$, and dural tear in two $(2 \%)$. No patients had delirium or neurological deterioration.

\section{Clinical outcomes by old-version JOA scores and the JOACMEQ}

The mean preoperative JOA score was $11.3 \pm 2.8$, and the score at final follow-up was $13.8 \pm 2.6$. Statistical analysis showed significant functional recovery after laminoplasty
Table 1 Demographics and clinical condition of 126 patients treated by laminoplasty

\begin{tabular}{ll}
\hline Variable & Mean or percentage \\
\hline Gender $(\%)$ & 81 male \\
Age (years) & $63.8 \pm 11.1(32-86)$ \\
Body mass index $\left(\mathrm{kg} / \mathrm{m}^{2}\right)$ & $24.7 \pm 3.5(17.2-34.2)$ \\
Duration of symptoms (months) & $35.1 \pm 50.0(1-360)$ \\
Comorbidities (\%) & 58 \\
Hypertension $(\%)$ & 33 \\
Diabetes mellitus (\%) & 15 \\
Cardiac disease $(\%)$ & 9 \\
Renal disease $(\%)$ & 2 \\
Malignant tumor $(\%)$ & 8 \\
Cerebrovascular disease $(\%)$ & 4 \\
Respiratory disease (\%) & 2 \\
Connective tissue disease $(\%)$ & 0 \\
Psychiatric disease (\%) & 2 \\
Diagnosis (\%) & \\
CSM & 64 \\
OPLL & 36 \\
\hline
\end{tabular}

CSM cervical spondylotic myelopathy, OPLL ossification of the posterior longitudinal ligament

Table 2 Surgical characteristics and perioperative information

\begin{tabular}{ll}
\hline Operative duration (min) & $88.9 \pm 33.7(32-209)$ \\
Number of operated laminae & $4.8 \pm 1.0(2-9)$ \\
Duration of hospital stay (days) & $15.6 \pm 5.3(8-42)$ \\
Perioperative complications (\%) & \\
$\quad$ Segmental motor paralysis & 4 \\
Surgical site infection & 1 \\
Hematoma & 2 \\
Dural tear & 2 \\
Delirium & 0 \\
Neurological deterioration & 0
\end{tabular}

$(P<0.01)$. Comparison of the scores in CSM versus OPLL patients revealed no significant differences at preoperation $(11.4 \pm 3.0$ vs. $11.2 \pm 2.5 ; P=0.66)$ or at the final follow-up $(13.8 \pm 2.7$ vs. $13.7 \pm 2.5 ; P=0.87)$.

The JOACMEQ results revealed an effective rate of $49 \%$ (53/109) for cervical spine function, 44\% (41/94) for upper extremity function, $41 \%(41 / 100)$ for lower extremity function, $17 \%$ (17/102) for bladder function, and $27 \%$ (33/124) for QOL (Fig. 1). These rates represented statistically significant differences according to the chi square test $(P<0.01)$. Multiple comparison with Bonferroni correction revealed that the effective rate for bladder function was significantly worse than the rates for cervical spine, upper extremity, and lower extremity functions 


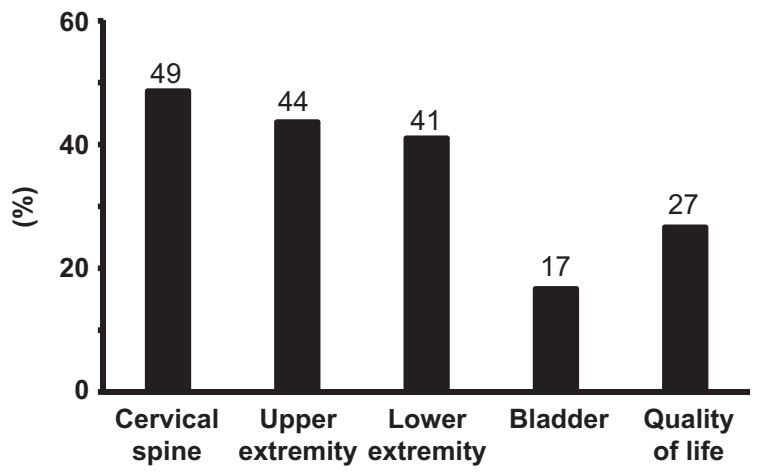

Fig. 1 Effective rate of each item in the Japanese Orthopaedic Association Cervical Myelopathy Evaluation Questionnaire for cervical myelopathy patients after single open-door laminoplasty

(all $P<0.01$ ). The rate for QOL was lower than that for cervical spine only $(P<0.01)$. The number of patients with both pretreatment and posttreatment scores $\geq 90$ was 17 in cervical spine function, 32 in upper extremity function, 26 in lower extremity function, 24 in bladder function, and 2 in QOL outcomes. The median score difference at the preoperation versus final follow-up was 0 (range -90 to +85 ) in cervical function, 5 (range -48 to +74 ) in upper extremity function, 0 (range -73 to +86 ) in lower extremity function, 0 (range -62 to +50 ) in bladder function, and 6 (range -56 to +70 ) in QOL.

The effective rates between CSM and OPLL patients were comparable in the cervical spine (52\% vs. $43 \% ; P=$ $0.34)$, upper extremity ( $41 \%$ vs. $47 \% ; P=0.58)$, lower extremity ( $38 \%$ vs. $46 \% ; P=0.44)$, and bladder functions $(18 \%$ vs. $15 \% ; P=0.78)$, and QOL ( $31 \%$ vs. $22 \% ; P=$ 0.30 ). The scores obtained in all the subitems also showed no significant differences between these two patient groups (cervical spine $P=0.60$; upper extremity $P=0.40$; lower extremity $P=0.97$; bladder function $P=0.63$; QOL $P=0.91)$.

Figure 2 shows the degree of preoperative and postoperative pain or numbness. Pain was significantly reduced in the neck or shoulders (from $4.4 \pm 3.1$ to $3.8 \pm 3.0 ; P=$ $0.04)$, in the arms or hands ( $6.0 \pm 3.0$ to $4.2 \pm 3.2 ; P<0.01)$, and from the chest to toes $(4.1 \pm 3.3$ to $3.2 \pm 3.3 ; P<0.01)$ at the final follow-up. Tightness in the chest was similar before and after surgery $(1.0 \pm 2.2$ to $0.9 \pm 1.9, P=0.71)$.

\section{Radiographic findings}

There was little difference between the preoperative and follow-up intermediate $\mathrm{C} 2-\mathrm{C} 7$ angles $\left(11.6 \pm 9.9^{\circ}\right.$ to $12.5 \pm$ $10.7^{\circ} ; P=0.30$; Fig. 3 ), but there were significant decreases in the angles in the flexion $\left(-10.8 \pm 11.4^{\circ}\right.$ to $-3.7 \pm 10.8^{\circ}$; $P<0.01)$ and extension positions $\left(22.2 \pm 10.9^{\circ}\right.$ to $20.2 \pm$ $\left.11.2^{\circ} ; P=0.02\right)$. Consequently, the cervical ROM was

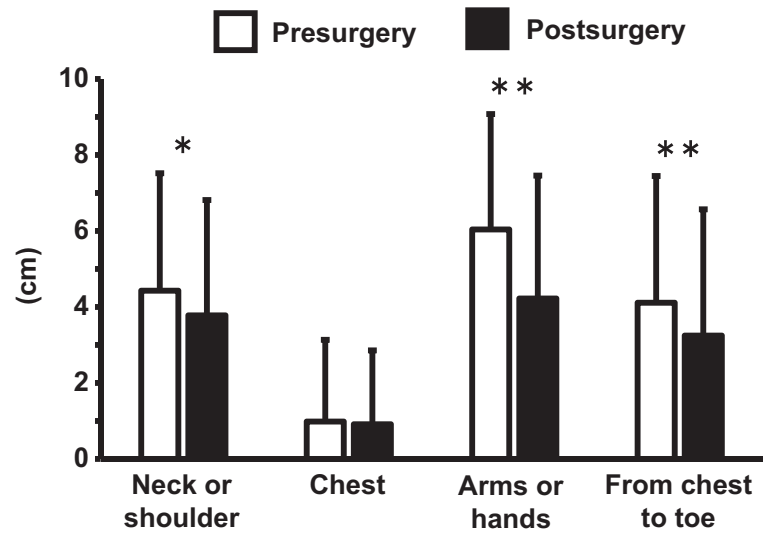

Fig. 2 Visual Analog Scale results for pain at different sites before and after surgery. At the final follow-up, pain was significantly reduced for all locations except the chest. $* P<0.05$; $* * P<0.01$

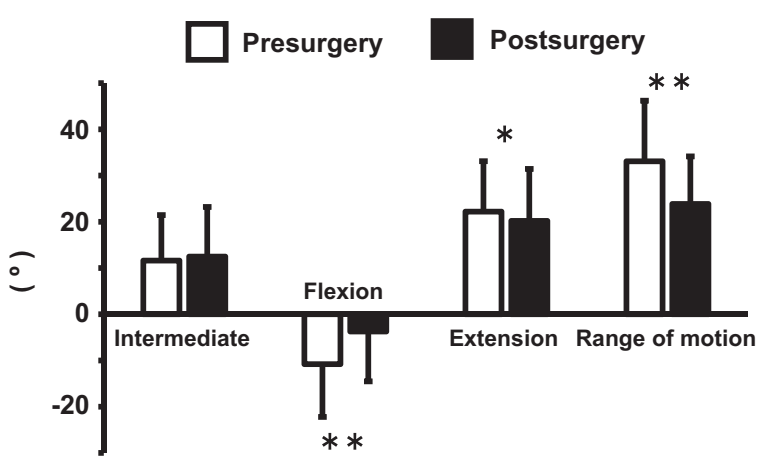

Fig. 3 Radiographic parameters before surgery and at the final followup. Compared to the preoperative values, the cervical alignment (C2-C7) angles at the final follow-up were significantly decreased in the effective group in the flexion and extension positions, consequently restricting the range of motion of the cervical spine. $* P<0.05$; $* * P<0.01$

significantly more restricted after surgery $\left(33.1 \pm 13.1^{\circ}\right.$; $P<0.01$ vs. $23.9 \pm 10.3^{\circ}$ ). When evaluating the angles for differential diagnosis, the ROM at preoperation was significantly wider in CSM than in OPLL patients (34.8 \pm $13.0^{\circ}$ vs. $\left.29.9 \pm 11.1^{\circ} ; P=0.05\right)$, while this difference became insignificant at the final follow-up $\left(24.7 \pm 8.1^{\circ}\right.$ vs. $22.1 \pm 11.8^{\circ} ; P=0.20$ ).

\section{Univariate and multivariate analyses: important indicators of surgical effectiveness}

Univariate analyses for each of the indicators under function/QOL was performed, and the results are shown in Supplementary table 1. Regarding cervical spine function, the $\mathrm{C} 2-\mathrm{C} 7$ angle alignment at the final follow-up was more lordotic in the effective therapy group than in the ineffective group, in both the intermediate position $\left(15.4 \pm 10.2^{\circ}\right.$ vs. $\left.10.3 \pm 10.8^{\circ} ; P=0.01\right)$ and the extension position $(24.0 \pm$ $10.3^{\circ}$ vs. $\left.17.7 \pm 12.4^{\circ} ; P<0.01\right)$. At the final follow-up, 
neck pain was reduced in the effective group but increased in the ineffective group $(-1.8 \pm 3.1$ vs. $0.3 \pm 3.5 ; P<0.01)$. Multivariate logistic regression analysis showed that laminoplasty was effective in patients with a reduction in neck pain (odds ratio $(\mathrm{OR}) 0.82, P<0.01)$ after surgery (Table 3).

For upper extremity function, a younger age at the time of surgery $(63.9 \pm 10.2$ vs. $68.4 \pm 8.4$ years; $P=0.03)$ and a reduction in neck or shoulder pain $(-1.4 \pm 3.1$ vs. $0.4 \pm 3.6$; $P=0.01)$ or arm or hand pain $(-2.9 \pm 3.3$ vs. $-0.6 \pm 3.3 ; P$ $<0.01)$ were indicators of success after laminoplasty. Multivariate analysis revealed only the decrease in arm or hand pain as a clinical indicator of better clinical outcomes (OR 0.80, $P<0.01$ ). For lower extremity function, patients with effective results were younger at the time of the operation $(59.4 \pm 10.9$ vs. $68.9 \pm 9.1$ years; $P<0.01)$ and noted a decrease in pain from the chest to toes after surgery $(-2.4 \pm 3.5$ vs. $0.1 \pm 3.0$ years; $P<0.01)$. Multivariate analysis revealed these two factors as indicators of effective therapeutic outcomes (OR for age 0.91, $P<0.01$; OR for change in pain $0.76, P<0.01$ ).

Univariate analysis revealed a reduction in neck or shoulder pain $(-2.4 \pm 3.2$ vs. $-0.1 \pm 3.4 ; P=0.02)$ as an indicator for therapeutic effectiveness in bladder function, but this difference was not statistically significant after Bonferroni correction. Thus, multivariate analysis was not possible. Patients with effective QOL improvement had a strong postoperative decrease in neck pain $(-2.1 \pm 3.0$ vs. $-0.1 \pm$ $3.5 ; P<0.01)$, arm or hand pain $(-4.1 \pm 3.4$ vs. $-1.0 \pm 3.1$; $P<0.01)$, and pain from the chest to toes $(-2.2 \pm 4.0 \mathrm{vs}$. $-0.4 \pm 2.7 ; P<0.01)$. Logistic regression analysis revealed that the indicator for better QOL recovery was reduced arm or hand pain (OR $0.75 ; P<0.01)$.

The surgical results, including the effective rates and clinical indicators, are summarized in Table 4.

\section{Discussion}

We used the JOACMEQ to clarify the clinical outcomes after single open-door laminoplasty for patients with cervical myelopathy. This surgical technique restored function in the cervical spine and extremities for $40-50 \%$ of the patients, but the improvement in bladder function was only minimal. A significant reduction in postoperative neck or shoulder pain was a clinical indicator of effective recovery of cervical spine function. A reduction in arm or hand pain favorably affected the postoperative upper extremity function. Higher age and poor relief of limb pain were indicators of ineffective surgical outcomes for lower extremity function. Finally, a postoperative decrease in pain in the upper extremities was a factor for enhanced QOL. Thus, the JOACMEQ made it possible to evaluate surgical outcomes precisely and to assess important factors for effective outcomes in patients with cervical myelopathy. Our results highlight the fact that laminoplasty is not uniformly effective for cervical myelopathy, and indicate that surgeons should evaluate each patient's postoperative pathological status with respect to both function and QOL.

Many studies on pain after laminoplasty focus on axial neck pain, which negatively affects clinical outcomes [22-27]. Our study extended these results, clarifying that neck or shoulder pain is an indicator of poor results for cervical function, such as the movements involved in drinking or looking up or down [10]. Our results showed that pain in the extremities negatively affected function. In particular, pain in the arms or hands directly degraded the QOL. These results specifically emphasize the importance of perioperative and postoperative pain management [25, 26, 28, 29]. To reduce pain, for example, it might be better to select laminectomy and fusion surgery over laminoplasty for patients with axial pain or a kyphotic
Table 3 Multivariate analysis for clinical indicators

Table 4 Summary of the surgical results at each domain of the JOACMEQ

\begin{tabular}{lllll}
\hline & Indicator & Odds ratio & $95 \%$ CI & $P$-value \\
\hline Cervical spine function & $\Delta$ VAS for neck or shoulder & 0.82 & $0.72,0.93$ & $<0.01$ \\
Upper extremity function & $\Delta$ VAS for arm or hands & 0.80 & $0.70,0.92$ & $<0.01$ \\
Lower extremity function & Age & 0.91 & $0.86,0.96$ & $<0.01$ \\
& $\Delta$ VAS from chest to toe & 0.76 & $0.64,0.91$ & $<0.01$ \\
Quality of life & $\Delta$ VAS for arm or hands & 0.75 & $0.65,0.86$ & $<0.01$ \\
\hline
\end{tabular}

$\Delta$ : change from the pre-op to post-op values

CI confidence interval, VAS Visual Analog Scale

\begin{tabular}{llllll}
\hline & Cervical & Upper extremity & Lower extremity & Bladder & QOL \\
\hline Effective rate $(\%)$ & 49 & 44 & 41 & 17 & 27 \\
Clinical indicator & Neck/shoulder pain & Arm/hand pain & Leg pain, age & - & Arm/hand pain \\
\hline
\end{tabular}

JOACMEQ Japanese Orthopaedic Association Cervical Myelopathy Evaluation Questionnaire, $Q O L$ quality of life 
preoperative C2-C7 alignment [26]. Moreover, postoperative analgesic agents should be considered, and new protocols for administering riluzole or intrathecal morphine may improve outcomes in the future [28, 29].

According to previous studies in patients who underwent fusion surgery for cervical myelopathy, the minimum clinically important difference (MCID) in the VAS is 2.53.1 for neck pain and 4.1 for arm pain [30-32]. In our results, the change in pre- and postoperative pain was 0.6 in the neck or shoulder and 1.8 in the arms or hands, neither of which appeared to reach the MCID. However, there are no reports evaluating the MCID in the VAS for patients who underwent single open-door laminoplasty, and therefore, further study will be necessary to validate the scores for this decompressive surgery.

Although studies have reported poor functional recovery for elderly patients after laminoplasty for cervical myelopathy, those studies evaluated neurological status using the old-version JOA score [33-36], so it is not possible to determine which neurological functions are adversely affected by advanced age. In the present study, the JOACMEQ scores revealed that age significantly impacted the function of the lower extremities after laminoplasty. This effect may be due to the decrease in the number of ventral horn cells and myelinated fibers in the spinal cord with advancing age [37-39]. Moreover, the prevalence of unrelated comorbidities, such as diabetic neuropathy, sarcopenia, or cardiopulmonary disorders, is inevitably higher in elderly patients, and these pathologies might impede the patients' ability to perform the tasks required in the JOACMEQ [33, 40]. However, after a prospective analysis of myelopathy patients, Nakashima et al. argued that even if neurological recovery was limited, the postoperative QOL improvement was comparable between elderly and younger populations [40]. Our data also suggested that age was not an indicator for QOL outcomes. Therefore, laminoplasty is recommended irrespective of age, and surgeons should explain the benefits and risks of surgical treatment based on the results of the present study.

In this study, single open-door laminoplasty did not provide a substantial improvement in bladder function. Similarly, Ohya et al. used the JOACMEQ to assess cervical OPLL patients who underwent double-door laminoplasty, and found no significant improvement in bladder function [19]. Because several populations with cervical myelopathy may have urologic disorders rather than neurogenic bladder symptoms, urodynamic or other appropriate tests should be used to determine whether other treatments can improve bladder function [41, 42]. Otherwise, the indications for laminoplasty should be revisited and other surgical methodologies considered, although there are no comparative studies of the impact of various techniques on bladder function.
Another shortcoming of single open-door laminoplasty is that it significantly restricts the cervical ROM. However, we previously evaluated postoperative factors affecting the neurological restoration after laminoplasty and found that the cervical ROM was more decreased in the group with sufficient recovery than in the one with poor recovery [43]. A more mobile cervical spine might be a disadvantage for postoperative recovery, since the spinal cord loses elasticity, especially in aged patients, and becomes vulnerable to dynamic stress. In addition, while the finding that cervical function improved despite the limited postoperative ROM might appear to be contradictory in our study, it is possible that the ROM limitation did not adversely affect the tasks that were required in the JOACMEQ. In fact, our analysis showed that the postoperative cervical function was not significantly influenced by the cervical ROM restriction $(P$ $<0.31$; Supplementary table 1). Instead, our results revealed that cervical function was significantly affected by neck pain. Therefore, the postoperative reduction in neck pain could have had a beneficial effect on the recovery of cervical function despite the restriction of the postoperative ROM.

Our study design did not allow us to compare whether the JOACMEQ or the old-version JOA score was better correlated with the clinical outcomes, due to the lack of positive controls for the symptoms. However, Fujiwara et al. compared the correlation between these two evaluation indices for upper extremity function, and revealed that the JOACMEQ was strongly correlated with upper arm performance (assessed by the Simple Test for evaluating Hand Function [44]), while the JOA scores were not [45]. Moreover, Hosono et al. reported that JOA scores have rater's bias, while the JOACMEQ scores do not, because of the nature of self-recording questionnaires [46]. Since the JOA score does not assess patients' satisfaction, disability, general health, or cervical function, the JOACMEQ can more comprehensively and appropriately evaluate the clinical outcomes for cervical myelopathy patients, and its reliability and validity have already been verified $[11,12]$.

This study had several limitations, including its retrospective nature. We did not evaluate the global spinal alignment, which also affects functional outcomes and QOL $[47,48]$. Differences in postoperative medication and rehabilitation, which were left to the surgeon's discretion, could have affected clinical outcomes. We combined data for CSM and OPLL patients, which occasionally present different pathologies and surgical outcomes [49, 50]. Further study will be necessary to compare the impact of these disorders on comprehensive postoperative function with a larger sample size. Finally, the results should be interpreted carefully, because this study was performed using a single surgical technique and assessment questionnaire at a single 
institute, and there was no control group with which to adjust for confounding factors.

In conclusion, the JOACMEQ provides a detailed analysis of multiple surgical outcomes and their clinical indicators for patients treated by cervical single open-door laminoplasty, and should be used in routine analyses of patient status and treatment efficacy.

\section{Data availability}

This can be found in the supplementary material.

Author contributions KW conceptualized this study. All authors were involved in designing the study. NN analyzed the data and mainly wrote this manuscript. All authors reviewed and approved the manuscript.

\section{Compliance with ethical standards}

Conflict of interest The authors declare that they have no conflict of interest.

Ethics approval This study was approved by our institution's review board. We certify that all applicable institutional regulations concerning the ethical use of human volunteers were followed during the course of this research.

Publisher's note: Springer Nature remains neutral with regard to jurisdictional claims in published maps and institutional affiliations.

\section{References}

1. Chiba K, Ogawa Y, Ishii K, Takaishi H, Nakamura M, Maruiwa $\mathrm{H}$, et al. Long-term results of expansive open-door laminoplasty for cervical myelopathy-average 14-year follow-up study. Spine (Phila Pa 1976). 2006;31:2998-3005.

2. Hirabayashi K, Miyakawa J, Satomi K, Maruyama T, Wakano K. Operative results and postoperative progression of ossification among patients with ossification of cervical posterior longitudinal ligament. Spine (Phila Pa 1976). 1981;6:354-64.

3. Hirabayashi K, Watanabe K, Wakano K, Suzuki N, Satomi K, Ishii Y. Expansive open-door laminoplasty for cervical spinal stenotic myelopathy. Spine (Phila Pa 1976). 1983;8:693-9.

4. Benzel EC, Lancon J, Kesterson L, Hadden T. Cervical laminectomy and dentate ligament section for cervical spondylotic myelopathy. J Spinal Disord. 1991;4:286-95.

5. Tetreault L, Kopjar B, Nouri A, Arnold P, Barbagallo G, Bartels $\mathrm{R}$, et al. The modified Japanese Orthopaedic Association scale: establishing criteria for mild, moderate and severe impairment in patients with degenerative cervical myelopathy. Eur Spine J. 2017;26:78-84.

6. Fehlings MG, Tetreault LA, Riew KD, Middleton JW, Wang JC. A clinical practice guideline for the management of degenerative cervical myelopathy: introduction, rationale, and scope. Global Spine J. 2017;7:21S-7S.

7. Kato S, Oshima Y, Oka H, Chikuda H, Takeshita Y, Miyoshi K, et al. Comparison of the Japanese Orthopaedic Association (JOA) score and modified JOA (mJOA) score for the assessment of cervical myelopathy: a multicenter observational study. PLoS ONE. 2015;10:e0123022.

8. Fukui M, Chiba K, Kawakami M, Kikuchi S, Konno S, Miyamoto $\mathrm{M}$, et al. An outcome measure for patients with cervical myelopathy: Japanese Orthopaedic Association Cervical Myelopathy Evaluation Questionnaire (JOACMEQ): part 1. J Orthop Sci. 2007;12:227-40.

9. Vernon H, Mior S. The Neck Disability Index: a study of reliability and validity. J Manip Physiol Ther. 1991;14:409-15.

10. Fukui M, Chiba K, Kawakami M, Kikuchi S, Konno S, Miyamoto M, et al. JOA Back Pain Evaluation Questionnaire (JOABPEQ)/ JOA Cervical Myelopathy Evaluation Questionnaire (JOACMEQ). The report on the development of revised versions. April 16, 2007. The Subcommittee of the Clinical Outcome Committee of the Japanese Orthopaedic Association on Low Back Pain and Cervical Myelopathy Evaluation. J Orthop Sci. 2009;14:348-65.

11. Fukui M, Chiba K, Kawakami M, Kikuchi S, Konno S, Miyamoto M, et al. Japanese Orthopaedic Association Cervical Myelopathy Evaluation Questionnaire (JOACMEQ): part 2. Endorsement of the alternative item. J Orthop Sci. 2007;12:241-8.

12. Fukui M, Chiba K, Kawakami M, Kikuchi S, Konno S, Miyamoto M, et al. Japanese Orthopaedic Association Cervical Myelopathy Evaluation Questionnaire: part 3. Determination of reliability. J Orthop Sci. 2007;12:321-6.

13. Fukui M, Chiba K, Kawakami M, Kikuchi S, Konno S, Miyamoto M, et al. Japanese Orthopaedic Association Cervical Myelopathy Evaluation Questionnaire (JOACMEQ): part 4. Establishment of equations for severity scores. Subcommittee on low back pain and cervical myelopathy, evaluation of the clinical outcome committee of the Japanese Orthopaedic Association. J Orthop Sci. 2008; 13:25-31.

14. Nikaido T, Kikuchi S, Yabuki S, Otani K, Konno S. Surgical treatment assessment using the Japanese orthopedic association cervical myelopathy evaluation questionnaire in patients with cervical myelopathy: a new outcome measure for cervical myelopathy. Spine (Phila Pa 1976). 2009;34:2568-72.

15. Azimi P, Rezaei O, Montazeri A. An outcome measure of functionality and quality of life in patients with cervical myelopathy. Iran Red Crescent Med J. 2014;16:e8102.

16. Chien A, Lai DM, Cheng CH, Wang SF, Hsu WL, Wang JL. Responsiveness of the Chinese versions of the Japanese Orthopaedic Association Cervical Myelopathy Evaluation Questionnaire and Neck Disability Index in postoperative patients with cervical spondylotic myelopathy. Spine (Phila Pa 1976). 2015;40:1315-21.

17. Witayakom W, Paholpak P, Jirarattanaphochai K, Kosuwon W, Sirichativapee W, Wisanuyotin $\mathrm{T}$, et al. Validation of the reliability of the Thai version of the Japanese Orthopaedic Association Cervical Myelopathy Evaluation Questionnaire (JOACMEQ). J Orthop Sci. 2016;21:124-7.

18. Nakashima H, Yukawa Y, Ito K, Machino M, Kanbara S, Morita $\mathrm{D}$, et al. Prediction of lower limb functional recovery after laminoplasty for cervical myelopathy: focusing on the 10-s step test. Eur Spine J. 2012;21:1389-95.

19. Ohya J, Oshima Y, Oka H, Saiki F, Taniguchi Y, Matsubayashi $\mathrm{Y}$, et al. Patient satisfaction with posterior decompression surgery for cervical ossification of the posterior longitudinal ligament: prognostic radiographic factors and patient-reported outcomes for the effectiveness of surgical treatment. World Neurosurg. 2016;96:272-9.

20. Ohya J, Oshima Y, Takeshita K, Oka H, Chikuda H, Taniguchi Y, et al. Patient satisfaction with double-door laminoplasty for cervical compression myelopathy. J Orthop Sci. 2015;20:64-70.

21. Oshima K, Iwasaki M, Sakaura H, Fujimori T, Nagamoto Y, Yoshikawa H. Comparison of the Japanese orthopaedic association score and the Japanese orthopaedic association cervical myelopathy evaluation questionnaire scores: time-dependent changes in patients with cervical spondylotic myelopathy and posterior longitudinal ligament. Asian. Spine J. 2015;9:47-53.

22. Ara T, lizuka H, Sorimachi $Y$, lizuka $Y$, Nakajima T, Nishinome $M$, et al. Evaluation of neck pain by using a visual analog scale before 
and after laminoplasty in patients with cervical myelopathy: relationship with clinical results. J Neurosurg Spine. 2010;12:635-40.

23. Kimura A, Endo T, Inoue H, Seichi A, Takeshita K. Impact of axial neck pain on quality of life after laminoplasty. Spine (Phila Pa 1976). 2015;40:E1292-8.

24. Kimura A, Shiraishi Y, Inoue H, Endo T, Takeshita K. Predictors of persistent axial neck pain after cervical laminoplasty. Spine (Phila Pa 1976). 2018;43:10-15.

25. Okada M, Minamide A, Endo T, Yoshida M, Kawakami M, Ando $\mathrm{M}$, et al. A prospective randomized study of clinical outcomes in patients with cervical compressive myelopathy treated with opendoor or French-door laminoplasty. Spine (Phila Pa 1976). 2009;34:1119-26.

26. Stephens BF, Rhee JM, Neustein TM, Arceo R. Laminoplasty does not lead to worsening axial neck pain in the properly selected patient with cervical myelopathy: a comparison with laminectomy and fusion. Spine (Phila Pa 1976). 2017;42:1844-50.

27. Yukawa $\mathrm{Y}$, Kato $\mathrm{F}$, Ito $\mathrm{K}$, Horie $\mathrm{Y}$, Hida $\mathrm{T}$, Ito $\mathrm{Z}$, et al. Laminoplasty and skip laminectomy for cervical compressive myelopathy: range of motion, postoperative neck pain, and surgical outcomes in a randomized prospective study. Spine (Phila Pa 1976). 2007;32:1980-5.

28. Hida T, Yukawa Y, Ito K, Machino M, Imagama S, Ishiguro N, et al. Intrathecal morphine for postoperative pain control after laminoplasty in patients with cervical spondylotic myelopathy. J Orthop Sci. 2016;21:425-30.

29. Moon ES, Karadimas SK, Yu WR, Austin JW, Fehlings MG. Riluzole attenuates neuropathic pain and enhances functional recovery in a rodent model of cervical spondylotic myelopathy. Neurobiol Dis. 2014;62:394-406.

30. Auffinger BM, Lall RR, Dahdaleh NS, Wong AP, Lam SK, Koski $\mathrm{T}$, et al. Measuring surgical outcomes in cervical spondylotic myelopathy patients undergoing anterior cervical discectomy and fusion: assessment of minimum clinically important difference. PLoS ONE. 2013;8:e67408.

31. Carreon LY, Glassman SD, Campbell MJ, Anderson PA. Neck Disability Index, short form-36 physical component summary, and pain scales for neck and arm pain: the minimum clinically important difference and substantial clinical benefit after cervical spine fusion. Spine J. 2010;10:469-74.

32. Parker SL, Godil SS, Shau DN, Mendenhall SK, McGirt MJ. Assessment of the minimum clinically important difference in pain, disability, and quality of life after anterior cervical discectomy and fusion: clinical article. J Neurosurg Spine. 2013;18:154-60.

33. Machino M, Yukawa Y, Hida T, Ito K, Nakashima H, Kanbara S, et al. Can elderly patients recover adequately after laminoplasty? A comparative study of 520 patients with cervical spondylotic myelopathy. Spine (Phila Pa 1976). 2012;37:667-71.

34. Maeno T, Okuda S, Yamashita T, Matsumoto T, Yamasaki R, Oda $\mathrm{T}$, et al. Age-related surgical outcomes of laminoplasty for cervical spondylotic myelopathy. Global Spine J. 2015;5:118-23.

35. Nagashima H, Morio Y, Yamashita H, Yamane K, Teshima R. Clinical features and surgical outcomes of cervical myelopathy in the elderly. Clin Orthop Relat Res. 2006;444:140-5.

36. Yoshida G, Kanemura T, Ishikawa Y, Matsumoto A, Ito Z, Tauchi $\mathrm{R}$, et al. The effects of surgery on locomotion in elderly patients with cervical spondylotic myelopathy. Eur Spine J. 2013;22:2545-51.
37. Terao S, Sobue G, Hashizume Y, Li M, Inagaki T, Mitsuma T. Age-related changes in human spinal ventral horn cells with special reference to the loss of small neurons in the intermediate zone: a quantitative analysis. Acta Neuropathol. 1996;92:109-14.

38. Terao S, Sobue G, Hashizume Y, Shimada N, Mitsuma T. Agerelated changes of the myelinated fibers in the human corticospinal tract: a quantitative analysis. Acta Neuropathol. 1994;88:137-42.

39. Zhang C, Goto N, Suzuki M, Ke M. Age-related reductions in number and size of anterior horn cells at C6 level of the human spinal cord. Okajimas Folia Anat Jpn. 1996;73:171-7.

40. Nakashima H, Tetreault LA, Nagoshi N, Nouri A, Kopjar B, Arnold PM, et al. Does age affect surgical outcomes in patients with degenerative cervical myelopathy? Results from the prospective multicenter AOSpine International study on 479 patients. J Neurol Neurosurg Psychiatry. 2016;87:734-40.

41. Fukuda K, Ozaki T, Tsumura N, Sengoku A, Nomi M, Yanagiuchi A, et al. Neurogenic bladder associated with pure cervical spondylotic myelopathy: clinical characteristics and recovery after surgery. Spine (Phila Pa 1976). 2013;38:104-11.

42. Misawa T, Kamimura M, Kinoshita T, Itoh H, Yuzawa Y, Kitahara J. Neurogenic bladder in patients with cervical compressive myelopathy. J Spinal Disord Tech. 2005;18:315-20.

43. Ogawa Y, Chiba K, Matsumoto M, Nakamura M, Takaishi H, Toyama Y. Postoperative factors affecting neurological recovery after surgery for cervical spondylotic myelopathy. J Neurosurg Spine. 2006;5:483-7.

44. Shindo K, Oba H, Hara J, Ito M, Hotta F, Liu M. Psychometric properties of the simple test for evaluating hand function in patients with stroke. Brain Inj. 2015;29:772-6.

45. Fujiwara H, Makino T, Yonenobu K, Honda H, Kaito T. Correlations and time-dependent changes of upper arm performance tests, the Japanese Orthopaedic Association score, and a newly developed patient-based outcome measure: the Japanese Orthopaedic Cervical Myelopathy Questionnaire. Bone Joint J. 2016;98-B:990-6.

46. Hosono N, Takenaka S, Mukai Y, Tateishi K, Fujiwara Y, Morishita Y, et al. Conventional JOA score for cervical myelopathy has a rater's bias-in comparison with JOACMEQ. J Orthop Sci. 2018;23:477-82.

47. Oshima Y, Takeshita K, Taniguchi Y, Matsubayashi Y, Doi T, Ohya $\mathrm{J}$, et al. Effect of preoperative sagittal balance on cervical laminoplasty outcomes. Spine (Phila Pa 1976). 2016;41:E1265-70.

48. Yoshida G, Alzakri A, Pointillart V, Boissiere L, Obeid I, Matsuyama $\mathrm{Y}$, et al. Global spinal alignment in patients with cervical spondylotic myelopathy. Spine (Phila Pa 1976). 2018;43:E154-62.

49. Fujiwara H, Oda T, Makino T, Moriguchi Y, Yonenobu K, Kaito T. Impact of cervical sagittal alignment on axial neck pain and health-related quality of life after cervical laminoplasty in patients with cervical spondylotic myelopathy or ossification of the posterior longitudinal ligament: a prospective comparative study. Clin Spine Surg. 2018;31:E245-51.

50. Nakashima H, Tetreault L, Nagoshi N, Nouri A, Arnold P, Yukawa $\mathrm{Y}$, et al. Comparison of outcomes of surgical treatment for ossification of the posterior longitudinal ligament versus other forms of degenerative cervical myelopathy: results from the prospective, multicenter AOSpine CSM-International Study of 479 patients. J Bone Joint Surg Am. 2016;98:370-8. 